\title{
Perspective
}

\section{@ Ketamine-Induced Urologic Insult (KIUI)}

Howard S. Smith, MD

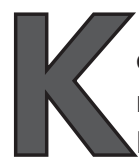

etamine initially introduced as an anesthetic agent in the 1960s, is a receptor complex antagonist n-methyl-d-aspartic acid that has been used as an anesthetic and/or analgesic for many years. In the past decade the use of ketamine as an analgesic or "analgesic adjuvant" appears to have increased. Subanesthetic doses of ketamine have been utilized for analgesia and opioid-sparing effects in chronic pain as well as in refractory cancer pain, and palliative medicine (1-11). Additionally, recently its use studied seems to have grown for chronic noncancer pain $(12,13)$. Its increased use studied overall has largely been for neuropathic pain and especially for the treatment of refractory complex regional pain syndrome (14-17). Ketamine has also been studied to reduce allodynia in patients with complex regional pain syndrome (18). Different routes of administration have been reported to produce beneficial results such as low-dose intranasal (S)-ketamine in patients with complex regional pain syndrome (18).

The mechanism of action has been considered to be mainly a noncompetitive antagonism of the N-methylD-aspartic acid (NMDA) receptor [19], however, its mechanisms of action may be extremely complex as ketamine may interact with multiple other receptors $(19,20)$. Ketamine has also been shown to inhibit tumor necrosis factor-alpha (TNF-alpha) and interleukin 6 (IL-6) gene expressions in lipopolysaccharide (LPS)-activated macrophages (21). It has even been speculated that the antiproinflammatory effects may be responsible for antihyperalgesic effects of ketamine (22).

The ketamine molecule contains a chiral carbon atom marking a chiral center. Ketamine can exist in two forms, or enantiomers; S-ketamine and R-ketamine. The physical properties of the enantiomers are identical, but their interactions with complex molecules, underlying PK/PD parameters, might differ (23). The elimination clearance of S-ketamine is more than that of R-ketamine (24).

Although anesthesiologists and pain specialists alike are familiar with the classic and common potential adverse effects of ketamine, they may not be as familiar with an increasingly recognized potential association of ketamine that clinicians should be aware of when prescribing ketamine. The observation that ketamine may lead to significant urological side-effects was first recognized in chronic ketamine recreational use (25-27).

In the South West of England, Cottrell and colleagues have reported increasing numbers of patients referred to urological services with complications of chronic ketamine use (28). Other cases have been reported in mainland Europe, Canada, Malaysia $(26,29)$ and the UK $(30)$.

Chen and colleagues discovered 4 female patients, ages 18 to 25 years, who presented to emergency department (ED) with urinary urgency, frequency, and pelvic pain, who had negative work-up and no response to antibiotic therapy were diagnosed with presumed interstial cystitis (31). More detailed history revealed that they were recreational ketamine users. Their symptoms significantly improved after stopping ketamine abuse (31).

Urological side effects to ketamine have been reported in the last 12 months as an emerging prob-

From: Albany Medical College, Albany, NY. Dr. Smith is Editor-in-Chief of Pain Physician, Associate Professor \& Academic Director of Pain Management, Albany Medical College, Albany, New York.

E-mail: smithh@mail.amc.edu Disclaimer: There was no external funding in the preparation of this manuscript. 
lem amongst the drug user population $(25,29,32)$. Storr and Quibell describe three patients where significant urological symptoms have arisen, possibly as a result of taking ketamine as an analgesic (33). Urinary tract symptoms are becoming increasingly recognized by ketamine abusers; $20-30 \%$ of frequent users reporting bladder symptoms $(25,34)$. Case series demonstrate a temporal link between ketamine use (abuse) and urological symptoms, urinary tract damage and renal impairment $(25,29,34)$, with some but not all improving on cessation of ketamine.

Chu and colleagues (25) reported lower urinary tract symptoms of ketamine-induced cystitis include: dysuria, frequency, urgency, incontinence, macroscopic hematuria and suprapubic pain. Investigations typically included negative urine culture (97\% in Chu study). Forty-two $(71 \%)$ patients had cystoscopy that showed various degrees of epithelial inflammation similar to that seen in chronic interstitial cystitis (25). All of 12 available bladder biopsies had histological features resembling those of interstitial cystitis showing various degrees of epithelial inflammation, ulceration, petechial haemorrhages, neovascularisation and contact bleeding. Urodynamically, either detrusor overactivity or decreased bladder compliance with or without vesico-ureteric reflux was detected to some degree in all of the 47 patients who agreed to have a video cystometrogram (VCMG) (25). Six of the 47 patients (13\%) showed vesicoureteral reflux (VUR) as a secondary event to the severely contracted bladder with high detrusor pressure. Thirty patients $(51 \%)$ had unilateral or bilateral hydronephrosis on renal ultrasonography, and four (7\%) showed features suggestive of papillary necrosis on radiological imaging. Eight patients had a raised serum creatinine level (25). Histology shows denuded bladder epithelium, often with eosinophilic infiltration within the lamina propria.

Tsai et al. reported eleven patients with urinary tract symptoms and a history of ketamine abuse (35). The most common complaints were lower urinary tract symptoms, including dysuria, frequency, urgency and gross hematuria. Urinalyses showed nonbacterial pyuria and were negative for tuberculosis. All biopsy specimens showed infiltrations of granulocytes (mostly eosinophils) and mast cells within the bladder tissue. Medications produced only slight clinical improvements. Intravesical instillation of hyaluronan solution was performed for some patients and significant improvement of lower urinary tract symptoms was observed (35).
Ketamine inhibits, in a dose-dependent manner, cardiovascular and visceromotor responses to the acute noxious stimulus of distension of the urinary bladder (36). This effect is likely related to NMDA receptor antagonist actions of ketamine, since other drugs with such pharmacologic properties produced a qualitatively similar inhibition (36). The main site of action of the drug appears to be localized to the spinal cord since intrathecal administration of inhibition of the mean arterial pressure changes ( $\triangle \mathrm{MAP}$ ) and electromyographic (EMG) to urinary bladder distention (UBD) (36).

Mason and colleagues reported a case series illustrates the harmful effects of ketamine on the urinary tract and the associated radiological findings. Delayed diagnosis can result in irreversible renal tract damage requiring surgical intervention (37).

Ultrasound demonstrated small bladder volume and wall thickening. CT revealed marked, generalized bladder wall thickening, mucosal enhancement, and perivesical inflammation. Ureteric wall thickening and enhancement were also observed. In advanced cases ureteric narrowing and strictures were identified using both CT and IVU (37).

One proposed mechanism for KIUI is that it only occurs in patients with a disorder of the urine-tissue interface (35). Thus, penetration of toxic urinary compounds (e.g. ketamine and/or its metabolites) into the bladder wall, as also seen in acute cystitis, may contribute to urinary urgency, frequency and pain (38).

Contact cystitis $(25,29)$ is another possible mechanism. Ketamine, norketamine and hydroxynorketamine can be measured in high quantities in the bladder. It is hypothesized that these directly trigger an inflammatory response through IgE, mast cell degranulation, eosinophil recruitment and enzyme release (25). Another theory proposed (25) is ketamine and its metabolites damage the microvasculature of the bladder potentially leading to the ischemia, fibrosis and abnormal neovascularisation identified on histology. Other suggested mechanisms include an autoimmune reaction (25).

Treatment of KIUI is to at least decrease the dose of ketamine and optimally to discontinue ketamine. Therapeutic strategies that may be useful may involve approaches aimed at repair of the urothelium. Elmiron (pentosan polysulfate sodium), a low molecular weight heparin-like compound, has been tried to rebuild the glycosaminoglycan (GAG) layer of the damaged urothelium and a few patients experienced symptom relief after treatment (29).

It appears that illicit synthetic ketamine obtainable 
illegally is reasonably "pure", since when a small amount which was secured with the aid of the Metropolitan Toronto Police Department Narcotics Division, was analyzed it contained only ketamine with trace amounts of dimethyl sulfoxide (29). It would seem unlikely that the urological insult associated with recreational ketamine use is due to excipients or contaminants from "street" ketamine. Thus, any potential associated bladder dysfunction/urological insult is probably largely at least partly due to direct local effects of ketamine and/or its metabolites.

Although, the potential association of ketamine dose and the incidence of urological insult is unknown; it seems that daily ketamine infusions administered at outpatient treatment centers for pain relief may go at least as high as $300 \mathrm{mg} / \mathrm{hr}$ (39). These doses should certainly be enough to potentially contribute to urological insult. Persson has postulated that long-term use ay be an important factor in potentially contributing to bladder dysfunction/urologic insult (40).

Although the reported cases have mainly concerned recreational drug users, they are relevant for ketamine used for legitimate long-term prescribed analgesic use as well (40). Persson successfully utilized long-term oral ketamine in efforts to achieve improved analgesia and a reduced opioid dose in a middle-aged patient who had a lumbar "disc herniated" and complained of severe post-surgical chronic low back and leg pain. After about a year of treatment, the patient started experiencing increased urinary frequency, however, if he lowered the ketamine dose the bladder symptoms diminished but the pain increased and vice versa (40).

As the use of ketamine in interventional pain medicine grows, interventional pain specialists should be aware of all the potential therapeutic effects and adverse effects of ketamine. Clinicians should assess for the development of symptoms and signs of bladder dysfunction/irritation in patients on ketamine therapy. Significant consideration should be given to decreasing the dose or discontinuing ketamine therapy in a patient who suddenly develops symptoms or signs of bladder dysfunction and/or irritation during treatment with ketamine.

\section{RefERENCES}

1. Legge J, Ball N, Elliott DP. The potential role of ketamine in hospice analgesia a literature review. Consult Pharm 2006; 21:51-57.

2. Lester L, Braude DA, Niles C, Crandall CS. Low-dose ketamine for analgesia in the ED: a retrospective case series. $A m$ J Energ Med 2010; 28:820-827.

3. Chazan S, Ekstein MP, Marouani N, Weinbroum AA. Ketamine for acute and subacute pain in opioid-tolerate patients. J Opioid Manage 2008; 4:173180.

4. Bell R, Eccleston C, Kalso E. Ketamine as an adjuvant to opioids for cancer pain. Cochrane Database Syst Rev 2003;(1):CDo03351.

5. Angst MS, Clark JD. Ketamine for managing perioperative pain I opioid-dependent patients with chronic pain: a unique indication? Anesthesiology 2010; 113:514-515.

6. Mercadante S, Lodi F, Sapio M, Calligara $M$, Serretta $R$. Long-term ketamine subcutaneous continuous infusion in neuropathic cancer pain. J Pain Symp- tom Manage 1995; 10:545-568.

7. Mercadante S, Villari P, Ferrera P, Arcuri E, David F. Opioid switching and burst ketamine to improve the opioid response in patients with movementrelated pain due to bone metastases. Clin J Pain 2009; 25:648-649.

8. Mercadante S, Arcuri E, Tirellu W, Casuccio A. Analgesic effect of intravenous ketamine in cancer patients on morphine therapy: a randomized, controlled, double-blind, crossover, double-dose study. J Pain Symptom Manage 2000; 20:246-252.

9. Mercadante S, Villari P, Ferrera P. Burst ketamine to reverse opioid tolerance in cancer pain. J Pain Symptom Manage 2003; 25:302-305.

10. Mercadante S, Arcuri E, Ferrera P, Villari $\mathrm{P}$, Mangione $\mathrm{S}$. Alternative treatments of breakthrough pain in patients receiving spinal analgesics for cancer pain. J Pain Symptom Manage 2005; 30:485-491.

11. Mercadante S. Ketamine in cancer pain: an update. Palliat Med 1996; 10:225-
230.

12. Bell RF. Ketamine for chronic non-cancer pain. Pain 2009; 141:210-214.

13. Noppers I, Niesters M, aarts L, Smith T, Sarton E, Dahan A. Ketamine for the treatment of chronic non-cancer pain. Expert Opin Pharmacother 2010; 11:2417-2429.

14. Elsewaisy O, Sion B, Monagle J. Analgesic effect of subanesthetic intravenous ketamine in refractory neuropathic pain: a case report. Pain Med 2010; 11:946-950.

15. Schwartzman RJ, Alexander GM, Grothusen JR, Paylor T, Reichenberger E, Perreault M. Outpatient intravenous ketamine for the treatment of complex regional pain syndrome: a doubleblind placebo controlled study. Pain 2009; 147:107-115.

16. Sigtermans MJ, van Hilten JJ, Bauer MC, Arbous MS, Marinus J, Sarton EY, Dahan A. Ketamine produces effective and long-term pain relief in patients with Complex Regional Pain Syndrome Type 1. Pain 2009; 145:304-311. 
17. Goldberg ME, Torjman MC, Schwartzman RJ, Mager DE, Wainer IW. Pharmacodynamic profiles of ketamine $(R)$ and (S)- with 5-day inpatient infusion for the treatment of complex regional pain syndrome. Pain Physician 2010; 13:379-387.

18. Finch PM, Knudsen L, Drummond PD. Reduction of allodynia in patients with complex regional pain syndrome: a double-blind placebo-controlled trial of topical ketamine. Pain 2009; 146:1825.

19. Chizh BA. Low dose ketamine: a therapeutic and research tool to explore $\mathrm{N}$ methyl-D-aspartate (NMDA) receptormediated plasticity in pain pathways. J Psychopharmacol 2007; 21:259-271.

20. Lois F, De Kock M. Something new about ketamine for pediatric anesthesia? Curr Opin Anaesthesiol 2008; 21:340-344.

21. WuGJ, Chen TL, Ueng YF, et al. Ketamine inhibits tumor necrosis factor-alpha and interleukin-6 gene expressions in lipopolysaccharide-stimulated macrophages through suppression of tolllike receptor 4-mediated c-Jun $\mathrm{N}$-terminal kinase phosphorylation and activator protein-1 activation. Toxicol Appl Pharmacol 2008; 228:105-113.

22. De Kock MF, Lavand'homme PM. The clinical role of NMDA receptor antagonists for the treatment of postoperative pain. Best Pract Res Clin Anaesthesiol 2007; 21:85-98.

23. Sinner B, Graf BM. Ketamine. Handb Exp Pharmacol 2008; 182:313-333.

24. Persson J, Hasselstrom J, Maurset $A$, et al. Pharmacokinetics and nonanal- gesic effects of S- and R-ketamines in healthy volunteers with normal and reduced metabolic capacity. Eur J Clin Pharmacol 2002; 57:869-875.

25. Chu PS, Ma WK, Wong SC, Chu RW, Cheng $\mathrm{CH}$, Wong S, Tse JM, Lau FL, Yiu MK, Man CW. The destruction of the lower urinary tract by ketamine abuse: a new syndrome? BJU Int 2008; 102:1616-1622.

26. Colebinders B, Van Erps P. Cystitis due to the of ketamine as a recreational drug: a case report. J Med Case Reports 2008; 2:219.

27. Oxley JD, Cotrell AM, Adams A, Gillatt D. Ketamine cystitis as a mimic of carcinoma in situ. Histopathology 2009; 55:705-708.

28. Cottrell AM, Ayres R, Weinstock P, Warren $\mathrm{K}$, Gillatt $\mathrm{D}$. Urinary tract disease associated with chronic ketamine use. MBJ 2008; 338:973.

29. Shahani R, Streutker C, Dickson B, Stewart RJ. Ketamine-associated ulcerative cystitis: a new clinical entity. Urology 2007; 69:810-12.

30. -McCambridge J, Winstock A, Hunt $\mathrm{N}$, Mitcheson L. 5-Year trends in use of hallucinogens and other adjunct drugs among UK dance drug users. Eur Addict Res 2007; 13:57-64.

31. Chen KT, Foo NP, Lin HJ. Frequent visits with urinary symptoms: subtle signs of ketamine abuse. Am J Emerg Me. 2008; 26:1061-1062.

32. Dhillon, BS, Nuttall, MC, Coull, N, O'Brien, TS. Minerva. BMJ 2008; 336: 898.
33. Storr TM, Quibell R. Can ketamine prescribed for pain cause damage to the urinary tract? Palliat Med 2009; 23:670-672.

34. Muetzelfeldt, L, Kamboja, SK, Ressa, H, Taylora, J, Morgana, CJA, Currana, HV. Journey through the K-hole: Phenomenological aspects of ketamine use. Drug Alcohol Depend 2008; 95:219229.

35. Tsai TH, Cha TL, Lin CM, Tsao CW, Tang SH, Chuang FP, Wu ST, Sun GH, Yu DS, Chang SY. Ketamine-associated bladder dysfunction. Int J Urol 2009; 16:826829.

36. Castroman PJ, Ness TJ. Ketamine, an Nmethyl-d-aspartate Receptor Antagonist, Inhibits the Spinal Neuronal Responses to Distension of the Rat Urinary Bladder. Anesthesiology 2002; 96:1410-1419.

37. Mason K, Cottrell A, Corrigan AG, Gillatt DA, Mitchelmore AE. Ketamine-associated lower urinary tract destruction: a new radiological challenge. Clin Radiol 2010; 65:795-800.

38. Riedl CR, Engelhardt PF, Daha KL, Morakis N, Pflüger $\mathrm{H}$. Hyaluronan treatment of interstitial cystitis/painful bladder syndrome. Int Urogynecol J Pelvic Floor Dysfunct 2008; 19: 717-721.

39. Kirkpatrick AF. Regarding Bell and Moore, Intravenous ketamine for CRPS: Making too much of too little? Pain 2010; In Press.

40. Persson J. Wherefore ketamine? Curr Opin Anaesthesiol 2010; 23:455-460. 